\title{
Analysis of flow field characteristics of cycloidal pump based on fluid solid interaction
}

\author{
Liu Yong $^{1} \cdot$ Huang Longlong ${ }^{1} \cdot$ Xu Jingsong $^{2} \cdot$ Wang Yanhua ${ }^{1}$
}

Received: 9 December 2020 / Accepted: 4 August 2021 / Published online: 28 September 2021

(c) The Author(s) 2021

\begin{abstract}
At present, in the aspect of numerical simulation of a cycloid pump, most researchers are based on CFD (computational fluid dynamics) to analyze the pump under different operating conditions (such as speed, temperature), and the performance of a pump under FSI (fluid solid interactions) is rare. Firstly, a model of cycloidal pump is established in COMSOL. The simulation results obtained by applying CFD and FSI are verified by experiments. Then, the flow in the rotating region and the inlet and outlet cavities are analyzed. Finally, through further analysis of the internal flow, improved design scheme of the cycloid pump is put forward, the inlet flow of the cycloid pump increased by $5.8 \%$ compared with the unoptimized, the inlet flow pulsation decreased by $32.7 \%$. The discharge flow of the cycloid pump increased by $16.3 \%$, the pulsation rate of discharge flow decreased by $47 \%$. It provides a reference for other pump research, analysis and improvement design.
\end{abstract}

Keywords Cycloidal pump $\cdot$ FSI $\cdot$ Numerical simulation $\cdot$ COMSOL $\cdot$ Improvement design

\section{Introduction}

An oil pump is an essential part of a hydraulic system. Because of small fluctuation, good performance, high accuracy, compactness and simplicity, the hypocycloid pump is widely used in the automotive industry for fuel lift, engine oil and transmission systems. In geometric theory, Saegusa introduced the formation of rotor profile of a hypocycloid oil pump [1]. Fabiani calculated the volume between teeth quantitatively by integral-derivative approach and the new derivative-integral approach [2]. Hao Liu deduced the equation

Technical Editor: Daniel Onofre de Almeida Cruz.

Liu Yong

Yongliu_epe@nuc.edu.cn

Huang Longlong

s1716021@st.nuc.edu.cn

Xu Jingsong

13934516585@139.com

Wang Yanhua

1550581187@qq.com

1 School of Energy and Power Engineering, North University of China, Taiyuan, Shanxi, China

2 China Weapon Industry Inner Mongolia First Machinery Manufacturing, Baotou City, Inner Mongolia, China of cycloid tooth profile by inner rolling method and carried out numerical calculation [3]. Hwang and Hsieh put forward a mathematical model to improve pump efficiency and derived dimensionless rootless equation [4]. Based on theoretical research, many scholars have constructed new tooth profiles. Choi inserted arc curve between inner cycloid and outer cycloid to form the equation of rotor tooth profile with no upper limit of eccentricity, thus avoiding undercutting [5]. Jung designed the rotor profile formed by multi-section curve (ellipse-involute-ellipse), which eliminates oil trapping [6]. Frosina used one-dimensional commercial program to build pump model and validate it with experimental data. In the field of numerical simulation, many scholars have improved the model [7]. Gamez-Montero and Castilla used the contact point viscosity model to simulate the solid-solid contact between gears $[8,9]$. In order to visualize the simulation results, many scholars use three-dimensional numerical simulation. Rundo introduced the method of the $0-3 \mathrm{D}$ model used for the analysis of the oil pump [10]. Natchimuthu uses FLUENT to simulate the fluid dynamics of the oil pump [11]. Frosina et al. uses PumpLinx to simulate and analyze the oil pump of a motorcycle engine made by Aprilia Company [12]. Based on the CFD simulation, many scholars analyze the pump structure and operation conditions. Suresh Kumar considered various operating conditions of the pump [13, 14]. Zhang, Perng, Laverty study the effects of the inlet 
pressure, tip clearance, porting and the metering groove geometry on pump flow performance and pressure ripples through the large number of CFD simulations [15]. After model validation, Altare and Rundo changed several geometric characteristics to analyze the influence on the pump performance [16]. Frosina mainly studied the effect of cavitation on the pressure and flow rate for the oil pump [17]. Gamez-Montero and Ruvalcaba studied the effect of leakage caused by clearance on pump performance $[8,18]$. Some people have studied the performance of the pump under fluid solid interactions. Ahamed used COMSOL Multiphysics to study the fluid-structure interaction of a Peristaltic Pump [19]. Takashi and Sarrate described the equations of motion of the fluid and rigid body with translation and rotation motion [20, 21]. Klaus-Jürgen Bathe and Dettmer W introduced the finite element discretization equations for fluid, structure and the coupling interface and described the solution procedures for fluid-structure interaction [22, 23].

Firstly, the cycloidal pump test-bed is built and tested (Sect. 1), and then, the numerical model of cycloid pump is established, and the CFD and FSI simulation analysis of cycloid pump is carried out, and the feasibility of the simulation model is verified by experiments (Sect. 2). Then, the flow in the rotating region and the inlet and outlet cavities of the cycloid pump are analyzed in detail (Sect. 3). Finally, based on the analysis of the flow field, the optimization scheme of the cycloid pump is proposed and the feasibility of the optimization method is verified (Sect. 4).

\section{Test rig}

\subsection{Parameters of tested pump}

Table 1 shows the performance parameters of the experimented pump, and Table 2 shows the physical parameters of the lubricating oil.

\subsection{Building experiment bench}

\subsubsection{Selection of experiment bench equipment}

Figure 1 is the physical connection diagram of cycloidal pump experiment bench, the main equipment used are

Table 1 Performance of experimented pump

\begin{tabular}{lllll}
\hline Type & $\begin{array}{l}\text { Rated } \\
\text { discharge/L/ } \\
\text { min }\end{array}$ & $\begin{array}{l}\text { Rated pres- } \\
\text { sure/MPa }\end{array}$ & $\begin{array}{l}\text { Rated } \\
\text { speed/r/min }\end{array}$ & $\begin{array}{l}\text { Volumetric } \\
\text { efficiency\% }\end{array}$ \\
\hline BB-B10 & 10 & 2.5 & 1450 & $\geq 90$ \\
\hline
\end{tabular}

Table 2 Physical parameters of lubricating oil

\begin{tabular}{ll}
\hline Oil type & L-HM46 \\
\hline Viscosity @ $40{ }^{\circ} \mathrm{C} / \mathrm{mm}^{\wedge} 2 / \mathrm{s} /$ & 47.5 \\
Viscosity Index & 98 \\
Density $12{ }^{\circ} \mathrm{C} / \mathrm{kg} / \mathrm{m}^{\wedge} 3 /$ & 890 \\
Preference pressure $/ \mathrm{Pa}$ & 101,325 \\
\hline
\end{tabular}

(a) Variable frequency motor: motor model: YVF1601-4 pole, nominal power: $15 \mathrm{~kW}$, nominal current: $30.1 \mathrm{~A}$, rated torque: $95.5 \mathrm{~N} \bullet \mathrm{m}$

(b) Frequency converter: frequency converter model: VDF9000, power: $18 \mathrm{~kW}$, temperature range:$10 \sim 40{ }^{\circ} \mathrm{C}$.

(b) Dynamic torque sensor: model: JN-DN, experimental range: $0 \sim 500 \mathrm{~N} \bullet \mathrm{m}$, operating temperature: $-20 \sim 60{ }^{\circ} \mathrm{C}$, torque indication error: $< \pm 0.5 \% \mathrm{f} \bullet \mathrm{s}$.

(c) Pressure transmitter: model: MIK-P310, experimental range: $0 \sim 2.5 \mathrm{MPa}$, accuracy class: 0.3 , medium temperature: $-10 \sim 70{ }^{\circ} \mathrm{C}$.

(d) Temperature transmitter: model: MIK-P202, experimental range: $-50 \sim 350{ }^{\circ} \mathrm{C}$, accuracy class: 0.5 .

(e) Turbine flowmeter: model: LWGY-MIK-DN10, experimental range: $0.2 \sim 1.2 \mathrm{~m}^{3} / \mathrm{h}$, temperature: $-20 \sim 120{ }^{\circ} \mathrm{C}$, temperature of operating environment: $-20 \sim 60{ }^{\circ} \mathrm{C}$, accuracy class: class 1 .

\subsubsection{Operation of experiment bed}

The structure of the experiment bed is as follows: connect the motor 1 , the torque meter 3 and the pump shaft 4 through the coupling 2, so that the motor can drive the pump to run and the speed and torque are tested by the torque meter. The inlet and outlet oil pipes are connected with the oil tank 11 to form a closed loop. During operation, pressure gauge 5-1 and pressure transmitter 6-1 can monitor the pressure at the outlet. In particular, the load on the pump is generated by the throttle valve 9 and proportional overflow valve 10 . Next to the valve is the flow sensor, which can test the instantaneous flow characteristics at the outlet.

\subsubsection{Test error analysis}

The test error mainly comes from the sensor error and the test-bed pipeline error. The accuracy grade of the pressure sensor is 0.3 , the range of the sensor is $0 \sim 2.5 \mathrm{MPa}$, and the error is $\pm 7.5 \mathrm{kPa}$. When the measured value is $0.15 \mathrm{MPa}$, the actual measured pressure value is $0.1425 \sim 0.1575 \mathrm{MPa}$; the accuracy grade of the flow sensor is 1 , the range is $3.3 \sim 20 \mathrm{~L} / \mathrm{min}$, and the error is $\pm 0.2 \mathrm{~L} / \mathrm{min}$. When the measured value is $10 \mathrm{~L} / \mathrm{min}$, the actual measured flow value is $9.8 \sim 10.2 \mathrm{~L} / \mathrm{min}$, because the flow and pressure pulsation of 


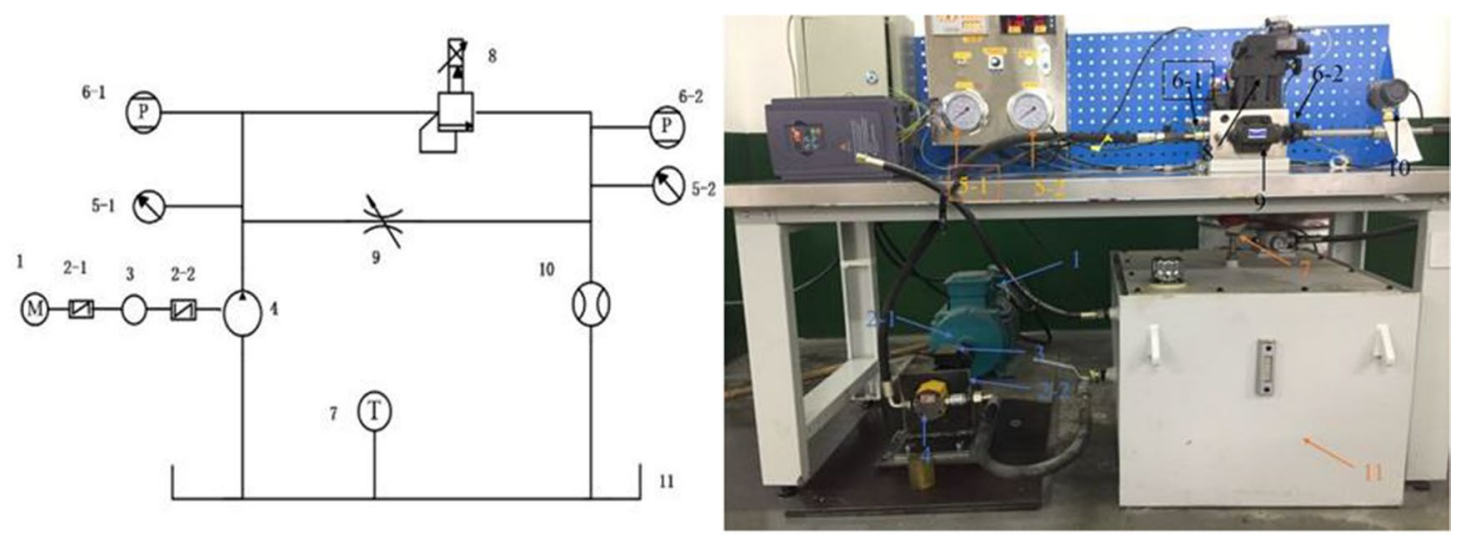

1.Electric machinery 2.Coupling 3.Rotating Speed and Torgue Sensor 4.gerotor pump 5.Pressure gauge 6.Pressure sensor 7.Temperature sensor 8.Relief overflow valve 9.throttle valve 10.Flow sensor 11.Tank

Fig. 1 Physical connection diagram of cycloidal pump experiment bench

the cycloid pump is small, such error will affect the transient flow and pressure. Rubber tube is used in the pipeline of the test-bed, which affects the fluctuation of flow and pressure, thus affecting the test accuracy.

\section{The hypocycloid gerotor pump}

\subsection{Basic principle of the cycloid}

The main parameters of the hypocycloid profile are eccentricity, number of teeth, generation coefficient $k$ and arc radius coefficient $h$. In this paper, the generation coefficient and arc radius coefficient which have the most significant influence on the tooth profile parameters are studied. Their definitions are as follows:

(1) Generating coefficient $k$ : the ratio of the distance from the center of rotation of the outer rotor to the center of the arc of the tooth profile and the radius of the outer rotor pitch circle.

(2) Arc radius coefficient $h$ : the ratio of the arc radius of the outer rotor tooth profile to the pitch radius of the outer rotor.

Their expressions are as follows:

$k=L / r_{2} \quad h=R / r_{2}$

where $L$-the distance between the center of rotation of outer rotor and the center of arc of tooth profile, $\mathrm{mm} ; r_{2}$ radius of a pitch circle of external rotor, $\mathrm{mm} ; R$-arc radius of outer rotor tooth profile, $\mathrm{mm}$.
Figure 2 is the schematic diagram of cycloid tooth profile formation.

Among them, the point $C_{1}$ is a cycloid formed by inner rolling method, the point $M$ is the meshing point of internal and external rotor profile, $r_{1}$ is the radius of the base circle and $r_{2}$ is the radius of the rolling circle, $L$ is radius of generating circle, $R$ is the radius of tooth circle.

The tooth profile equation of the inner rotor is shown in Formula (2).

$\left\{\begin{array}{l}x_{M 1}=L \cdot \cos \left(\phi_{2}-\phi_{1}\right)-R \cdot \cos \left(\phi_{2}+\theta-\phi_{1}\right)-a \cdot \cos \phi_{1} \\ y_{M 1}=L \cdot \sin \left(\phi_{2}-\phi_{1}\right)-R \cdot \sin \left(\phi_{2}+\theta-\phi_{1}\right)+a \cdot \sin \phi_{1}\end{array}\right.$

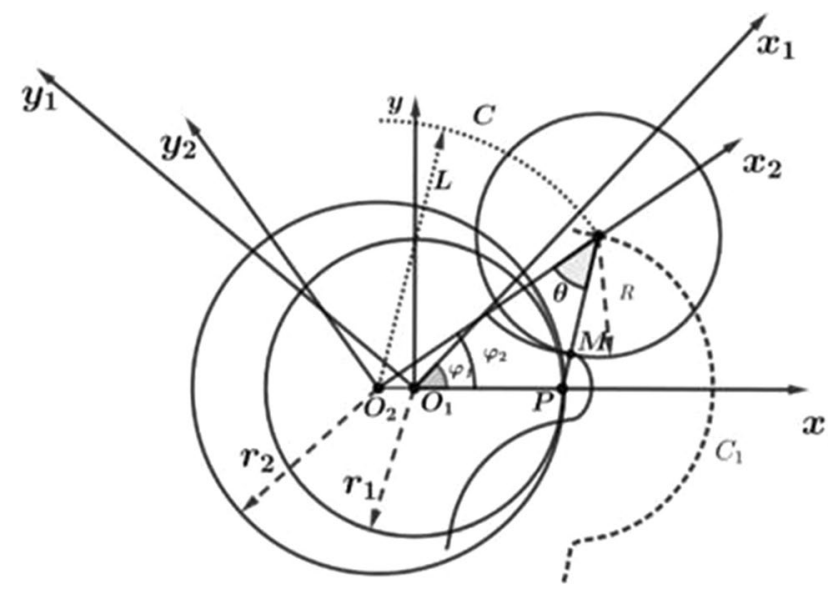

Fig. 2 Principles of tooth profile formation of cycloid rotor 
The relation of $\theta$ can be obtained from the meshing principle

$k \sin \theta=\sin \left(\theta+\phi_{2}\right)$

\subsection{Basic composition of cycloidal pump}

A hypocycloid pump consists of two main components: an outer rotor and an inner rotor that has one less tooth than the outer rotor. For a pump, the inner rotor centerline is positioned at a fixed eccentricity from the centerline of the outer rotor. Both gears rotate in the same direction but at different speeds because of the relation between the teeth, with the internal gear being slightly faster than the external gear. The angular velocity ratio is $\mathrm{Z}-1 / \mathrm{Z}$.

The geometry of the cycloidal pump is designed to numerically simulate the cycloid pump. Table 3 shows the specific structural parameters of the cycloidal pump.

\subsection{Basic principle of cycloid pump simulation}

\subsubsection{Basic equations of fluid solid interaction}

In the $A L E$ (Arbitrary Lagrangian-Eulerian) formulation, we can arbitrarily choose the standpoint to describe the governing equations, from the Lagrangian to the Eulerian, or the intermediate state, by specifying arbitrarily the distribution of the velocity of the reference points [22].

\section{(1) ALE description of the Navier-Stokes equation}

The momentum conservation law and the continuity equation for incompressible flow are formulated in the referential description as

$\frac{\partial \rho}{\partial \mathrm{t}}+\nabla\left(\rho \mathbf{u}_{\mathrm{f}}\right)=0$

$\rho \frac{\partial\left(\mathbf{u}_{\mathrm{f}}\right)}{\partial t}+\rho\left(\nabla \mathbf{u}_{\mathrm{f}}\right)\left(\mathbf{u}_{\mathrm{f}}-\hat{\mathbf{v}}\right)=\nabla \cdot \boldsymbol{\sigma}+\mathbf{F}$

where $\rho, \boldsymbol{F}$ and $\boldsymbol{\sigma}$ represent, respectively, the fluid density (SI unit: $\mathrm{kg} / \mathrm{m}^{3}$ ), the volume force vector (SI unit: $\mathrm{N} / \mathrm{m}^{3}$ ) and the stress tensor (SI unit: $\mathrm{Pa}$ ), $\boldsymbol{u}_{\mathrm{f}}$ is the velocity vector of the

Table 3 The specific structural parameters of the cycloidal pump

\begin{tabular}{ll}
\hline Radius of tooth circle $R / \mathrm{mm}$ & 9 \\
Radius of generating circle $L / \mathrm{mm}$ & 26 \\
Eccentricity $a / \mathrm{mm}$ & 2.5 \\
Rotor thickness $/ \mathrm{mm}$ & 14 \\
Face clearance between rotor and pump cover/mm & 0.05 to 0.1 \\
Pipe diameter/mm & 10
\end{tabular}

material particle, $\hat{\mathbf{v}}$ represents the mesh velocity. The velocity difference $\left(\mathbf{u}_{\mathrm{f}}-\hat{\mathbf{v}}\right)$ is denoted as the convective velocity.

$\boldsymbol{\sigma}=-p \mathbf{I}+\mu\left(\nabla \mathbf{u}_{\mathrm{f}}+\left(\nabla \mathbf{u}_{\mathrm{f}}\right)^{T}\right)$

where $p$ represents the static pressure, $\mu$ denotes the fluid viscosity, $\boldsymbol{I}$ is the second-order identity tensor.

\section{(2) Structure equation}

The equation of structural motion is shown in Formula (6).

$\rho \frac{\partial^{2} d}{\partial t^{2}}=\nabla \cdot \sigma_{s}+F_{b}$

$\rho$ is the material density, $d$ is the vector of structure displacement, $\sigma_{\mathrm{s}}$ is Second Piola-Kirchhoff stress, $F_{\mathrm{b}}$ is the volume force vector.

In this paper, the rotor has translation and rotation motion, and its discretized equations can be expressed as follows.

$m_{i} \ddot{d}_{i}+c_{i} \dot{d}_{i}+k_{i} d_{i}=F_{i}$

$m_{\theta} \ddot{\theta}_{i}+c_{\theta} \dot{\theta}_{i}+k_{\theta} \theta_{i}=M_{i}$

where displacements $d_{i}$ are the components of the solid translation, whereas the angle $\theta$ describes the solid rotation, $m_{i}, c_{i}, k_{i}, m_{\theta}, c_{\theta}$ and $k_{\theta}$ denote the mass, the damping and the stiffness moduli for the translational and rotational degrees of freedom, respectively. The quantities $F$ and $M$ represent the force, and the moment exerted by the solid on the fluid $\left(F_{i}, M_{i}\right.$ are the component of $F$ and $\left.M\right)$.

\section{(3) Fluid-solid interaction}

On the fluid-structure interface $\Gamma_{\mathrm{f}-\mathrm{s}}$, in which a viscous fluid flow is interacting with a solid, equilibrium and compatibility conditions must be satisfied at the fluid-structure interface [22]. These conditions are

$$
\begin{aligned}
& \int_{f-s} \sigma_{f} n d a=-F, \int_{f-s} \Delta x \times\left(\sigma_{f} n\right) d a=-M \\
& u_{f}-\dot{d}=0 \\
& \left(u_{f}-\hat{v}\right) \cdot n=0
\end{aligned}
$$

Also, on $\Gamma_{\mathrm{f}-\mathrm{s}}, n$ is the outward normal to the boundary, the total force exerted on the solid boundary by the fluid is the negative of the reaction force on the fluid, the motion of the fluid on the $\Gamma_{\mathrm{f}-\mathrm{s}}$ transformed from the solid, the velocity $\hat{v}$ of the reference frame and the positions $\hat{x}$ need to satisfy the consistency condition. 


\subsection{Solution methods: description and details}

The simulations presented here were carried out with the commercial algorithm COMSOL Multiphysics, which is based on the finite element method [19]. In the present case, using $P 1+P 1$ discretization format, the delivery pressure was imposed at the end of the outlet port, while the atmospheric pressure was set on the inlet port. Mumps solver for linear problems and AMG algebraic multigrid solver is generally used to solve the flow field problems, which can better solve the nonlinear problems. The residual scaling uses 1e-3. Due to the serious deformation of the grid in the rotating region, it is necessary to re-divide the grid when the mesh distortion is greater than 2 .

\subsubsection{Model construction}

Figure 3 is the model established during the fluid solid interactions simulation, and Table 4 is the physical parameters of the fluid and the solid.

\subsubsection{Boundary condition setting}

\section{(1) Boundary conditions of the fluid region}

For the specific boundary conditions of the fluid domain, the inlet is local atmospheric pressure, and the outlet is $0 \sim 2.5 \mathrm{MPa}$. The static region and the dynamic region adopt the identity pairs to ensure the data transmission. Specify the fluid boundary movement of the inner and outer rotors. The dynamic deformation domain adopts ALE method, and the specific boundary conditions are set as shown in figure 4 .

(2) Boundary condition setting of fluid solid interactions region

Figure 5a shows the setting of the coupling interface between the inner and outer rotors and the fluid between

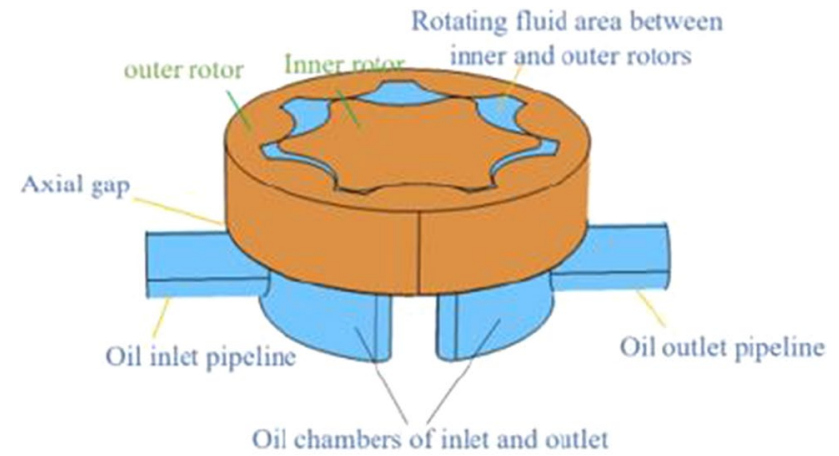

Fig. 3 FSI model of cycloidal pump
Table 4 Basic physical parameters of fluid and solid

\begin{tabular}{llll}
\hline Fluid & \multicolumn{3}{l}{ Solid } \\
\hline Density $/ \mathrm{kg} / \mathrm{m}^{3}$ & 890 & Density $/ \mathrm{kg} / \mathrm{m}^{3}$ & 7850 \\
Dynamic viscosity $/ \mathrm{Pa} \cdot \mathrm{s}$ & 0.2115 & Young modulus $E / \mathrm{Pa}$ & $200 \mathrm{e} 9$ \\
Temperature $/{ }^{\circ} \mathrm{C}$ & 12 & Poisson's ratio & 0.3 \\
\hline
\end{tabular}

them, and Figure $5 \mathrm{~b}$ shows the setting of the coupling interface between the inner and outer rotors and the axial leakage field.

\subsubsection{Grid generation}

There is a gap of $0.1 \mathrm{~mm}$ between the inner and outer rotors in the rotating area, so the minimum grid size should be set as $0.01 \mathrm{~mm}$, and the maximum grid size should not be too large. For the rotating area and the leaking area, the sweeping grid is used, and the free tetrahedral grid is used for another static fluid. The specific grid is shown in Figs. 6, 7.

\subsubsection{Grid independence study}

The details of the grid independence study are provided in Table 5 and Fig. 8. Table 5 shows mean normalized flow, and Fig. 8 shows the instantaneous flow at the outlet for two mesh sizes.

Through analysis, it is shown that the error in the mean normalized flow is $0.28 \%$ and $0.68 \%$ for the flow pulsation rate. Considering this minimum error (Fig. 8) and the performance of the central processing unit, the simulation here is feasible with a grid of about 175,450 cells.

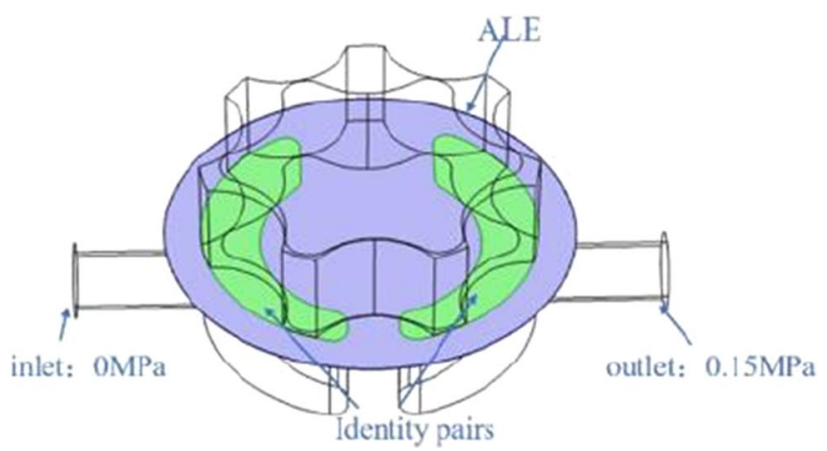

Fig. 4 Boundary condition setting of fluid field 
Fig. 5 Fluid solid coupling interface

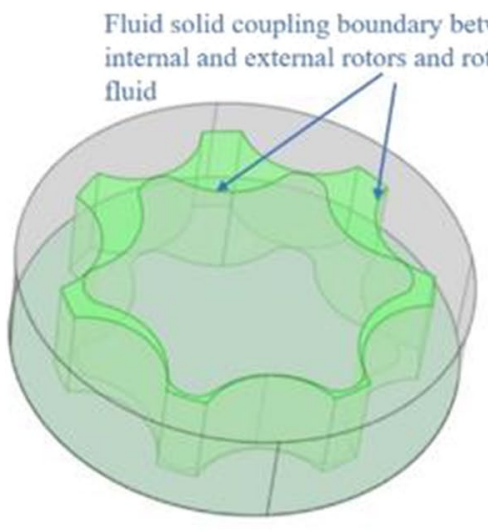

(a)

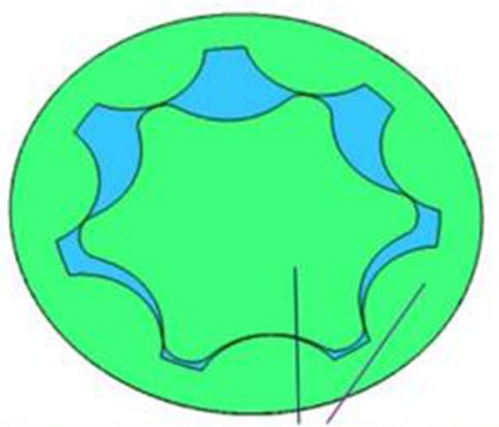

Coupling boundary between fluid and solid in axial leakage region

(b)

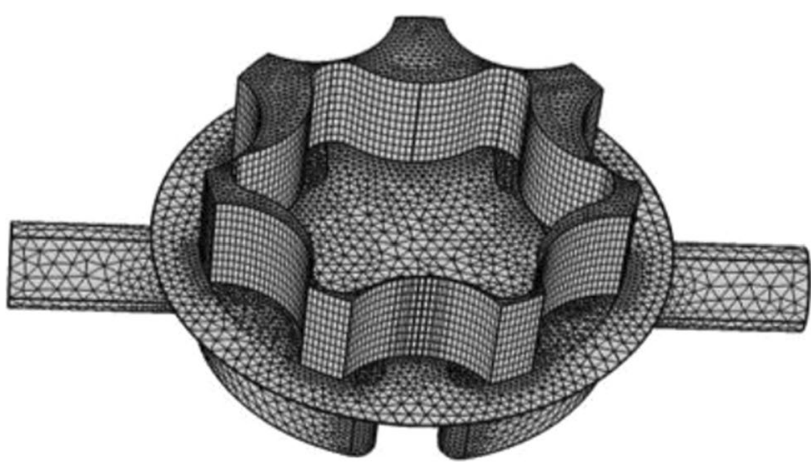

Fig. 6 Grid division of fluid domain

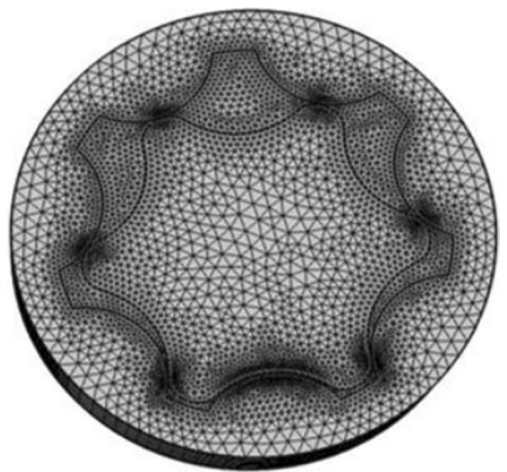

Fig. 7 Internal and external rotors and rotating fluid grids

Table 5 Mean normalized flow for two mesh sizes

\begin{tabular}{lll}
\hline $\begin{array}{l}\text { Number of mesh cells } \\
\left(\times 10^{6}\right)\end{array}$ & $\begin{array}{l}\text { Mean normalized flow/L/ } \\
\text { min }\end{array}$ & $\begin{array}{l}\text { flow } \\
\text { pulsation } \\
\text { rate/\% }\end{array}$ \\
\hline 0.17545 & 9.258 & 14.7 \\
0.32511 & 9.284 & 14.8 \\
\hline
\end{tabular}

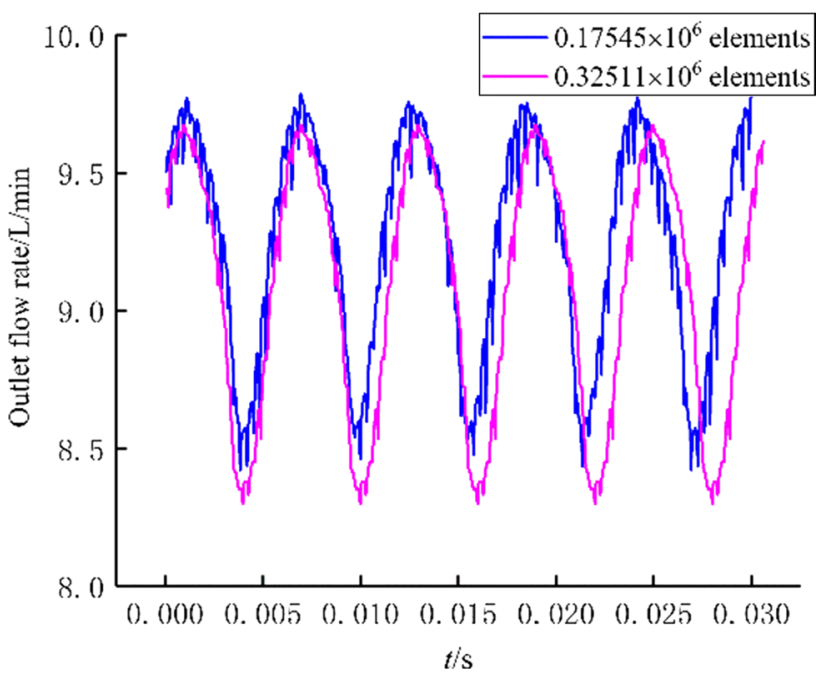

Fig. 8 the instantaneous flow at the outlet for two mesh sizes

\subsection{Model validation}

\subsubsection{Comparative analysis of outlet flow and pressure characteristics}

By analyzing the flow and pressure characteristic curve at the simulation outlet of CFD and FSI, and comparing with the experiment results, as shown in Fig. 9 and Fig. 10, the comparison of CFD, FSI and experiment is made.

The average value of flow and pressure, flow pulsation and pressure pulsation of CFD, FSI and experiment is analyzed. The formula is the average value of flow and pressure and the calculation formula of pulsation rate. Tables 6 and 7 are the specific calculation results, and the errors between CFD, experiment and FSI are compared. 


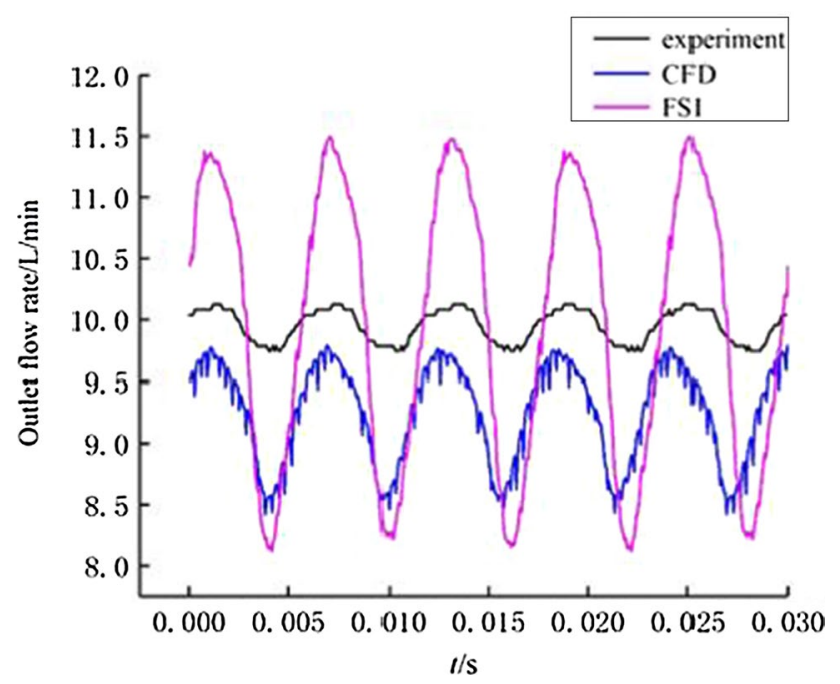

Fig. 9 Instantaneous flow fluctuation

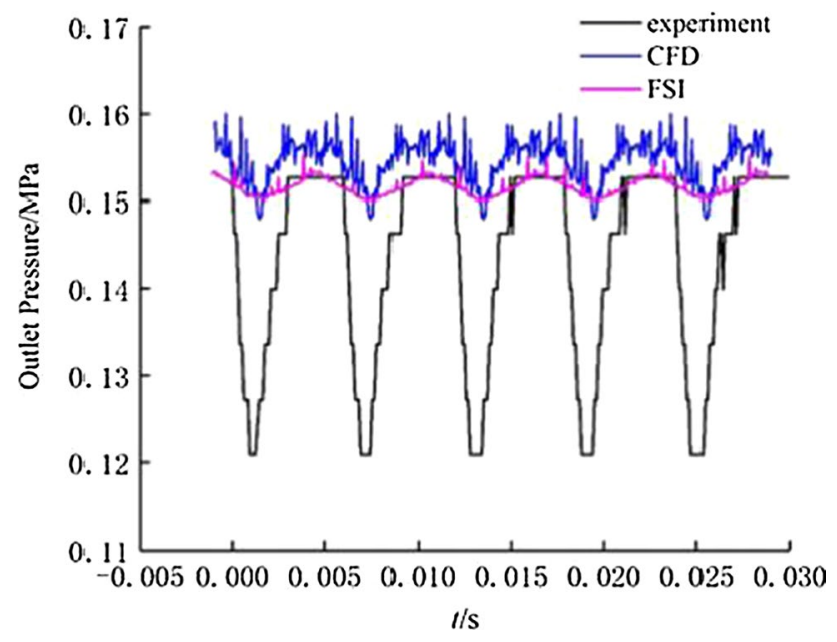

Fig. 10 Transient pressure fluctuation

Table 6 Comparative analysis of flow and pressure characteristics of CFD and FSI

\begin{tabular}{lllll}
\hline & $Q_{m} / \mathrm{L} / \mathrm{min}$ & $P_{m} / \mathrm{MPa}$ & $\delta_{Q} / \%$ & $\delta_{P} / \%$ \\
\hline CFD & 9.258 & 0.154 & 14.76 & 8.8 \\
FSI & 9.948 & 0.151 & 33.9 & 3.4 \\
Difference/\% & 6.9 & 2.0 & 63 & 159 \\
\hline
\end{tabular}

Table 7 Comparison and analysis of flow and pressure characteristics between experiment and FSI

\begin{tabular}{lllrl}
\hline & $Q_{m} / \mathrm{L} / \mathrm{min}$ & $P_{m} / \mathrm{MPa}$ & $\delta_{Q} / \%$ & $\delta_{P} / \%$ \\
\hline experiment & 9.911 & 0.143 & 3.9 & 26.7 \\
FSI & 9.948 & 0.151 & 33.9 & 3.4 \\
Difference/\% & 0.37 & 5.3 & 88.5 & 685 \\
\hline
\end{tabular}

$Q_{m}=\frac{\int Q_{s h} d t}{d t} P_{m}=\frac{\int P_{s h} d t}{d t}$

$\delta_{Q}=\frac{\left(Q_{s h}\right)_{\max }-\left(Q_{s h}\right)_{\min }}{Q_{m}}$

$\delta_{P}=\frac{\left(P_{s h}\right)_{\max }-\left(P_{s h}\right)_{\min }}{P_{m}}$

where $Q_{s h}$ and $P_{s h}$ are the average flow and pressure, respectively; $\delta_{Q}$ and $\delta_{P}$ are flow pulsation rate and pressure pulsation rate, respectively.

Through the analysis of Figs. 9, 10, Tables 6 and 7, it can be concluded that: (1) in terms of flow characteristics, the average flow value of FSI simulation is higher than that of test and CFD, but it is closer to the experiment value. The flow pulsation rate of FSI at the outlet is the largest, because the long rubber pipe is used for the outlet in the test, and it passes through the throttle valve, overflow valve and other components, and there is error on the test, resulting in very small flow fluctuation.

(2) In terms of pressure characteristics, the pressure average value of FSI and experiment at the outlet are lower than the CFD simulation value; the pressure mean value of FSI is closer to the CFD result, and the CFD and FSI results are more consistent with the pressure boundary condition at the outlet; compared with the pressure fluctuation of the CFD, FSI and experiment, the pressure fluctuation rate of CFD and FSI is relatively small, because of the complexity of the pipeline and the error of the parts such as the throttle valve, the overflow valve and the pressure sensor, the pressure pulsation rate at the outlet of the experiment is large.

Based on the above analysis, it is concluded that the results of experiment, CFD and FSI, are different mainly due to errors in numerical simulation and experiment. In terms of flow, FSI is closer to the experiment, and in terms of pressure, FSI and CFD are more in line with the actual situation.

Combined with the theoretical analysis of CFD and FSI, it is concluded that the interaction between fluid and solid is generated by the rotor driving fluid motion during the operation of the pump. Since CFD only specifies the motion along the motion interface, FSI not only generates the motion at the fluid solid coupling interface, but also is affected by the solid force. The coupling has a great influence upon the calculation results. Therefore, FSI simulation is closer to the reality.

\section{Flow field analysis of cycloidal pump based on FSI}

\subsection{Section analysis of rotation domain}

A section $(z=7 \mathrm{~mm})$ in the rotating region is selected to study the pressure distribution over the flow field based on 
FSI. Figure 11 shows the distribution of pressure on the section. A is a closed area that represents the whole process of change from the beginning of oil absorption to the end of oil pressure. $A_{0} \rightarrow A_{5}$ is the distribution of negative pressure and the other is positive pressure at the section.

Through the analysis of the pressure distribution of the rotating area, it can be concluded that: (1) the negative pressure: $A_{0} \rightarrow A_{2}>A_{3} \rightarrow A_{5}$. Because in the oil absorption stage, i.e., $A_{0} \rightarrow A_{5}$, as the oil suction, the pressure increases gradually that makes oil absorption capacity decrease gradually. (2) the positive pressure: $A_{6} \rightarrow A_{8}<A_{9} \rightarrow A_{11}$. Because in the oil discharge stage, i.e., $A_{6} \rightarrow A_{11}$, as the rotating volume decreases, the pressure increases gradually to discharge the oil.

\subsection{Analysis of cross section and longitudinal section of the oil inlet chamber}

The cross section of the oil inlet chamber $(z=-1 \mathrm{~mm})$ is selected to study the pressure distribution at the cross section. The pressure distribution at the cross section of the oil inlet chamber is shown in Fig. $12\left(\mathrm{~A}_{0} \rightarrow \mathrm{A}_{5}\right.$ corresponds to the motion of the rotating region).

By analyzing Fig. 12, it can be concluded that in the oil inlet chamber areas $A_{0} 、 A_{2} 、 A_{3}$ and $A_{5}$, the pressure on the right side is lower than that on the left side, which is consistent with the pressure distribution law in the rotating area; $\mathrm{A}_{1}$ and $\mathrm{A}_{4}$ show that the pressure on the left side is higher than that on the right side.

In order to further study the flow situation of the oil inlet chamber, the longitudinal section through the oil inlet chamber is selected for analysis. Figure 13a, b is the schematic diagram of the longitudinal section through the oil inlet chamber and its $x$ and $z$ coordinate distribution, respectively.

Figure 14 is the pressure and streamlines distribution diagram of the longitudinal section through the inlet chamber. $\mathrm{A}_{0} \rightarrow \mathrm{A}_{5}$ corresponds to the pressure distribution of the cross section of the rotation domain.

By analyzing Fig. 14, it can be concluded that in the area of the inlet chamber $A_{0} 、 A_{2} 、 A_{3}$, and $A_{5}$, the right side pressure is lower than the left side pressure, while $A_{1}$ and $\mathrm{A}_{4}$ appear that the left side pressure is greater than the right side pressure.

Through analysis for the streamline distribution, it is concluded that in the range of $--18 \mathrm{~mm}<x<-5 \mathrm{~mm}$ and in the area of $z<-8 \mathrm{~mm}$, due to the low negative pressure resulting in low oil absorption capacity, the liquid flows laterally, which may cause a large amount of liquid to fail to flow into the rotating area and reach the oil discharge chamber; in the range of $0 \mathrm{~mm}<x<15 \mathrm{~mm}$, due to the high negative pressure generated here, the oil absorption capacity is large. Most of the liquid still flows along the z-axis, but a small amount of lateral flow also occurs at $z<-8 \mathrm{~mm}$.

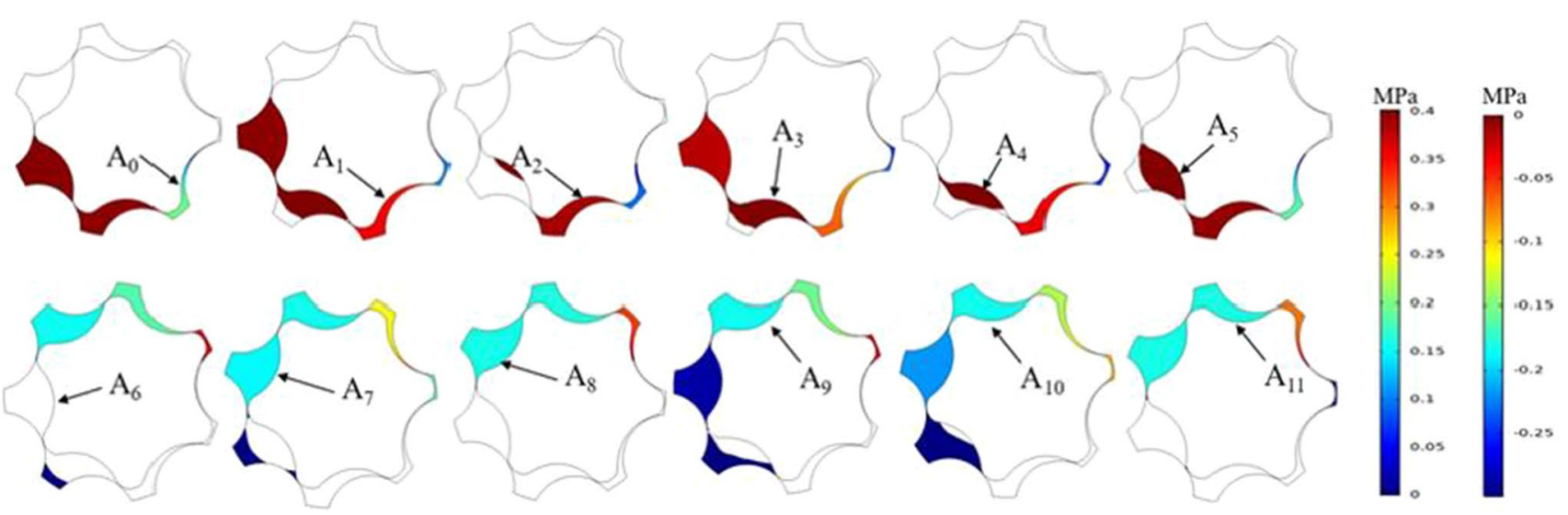

Fig. 11 Distribution of positive and negative pressure on a section in the rotating region

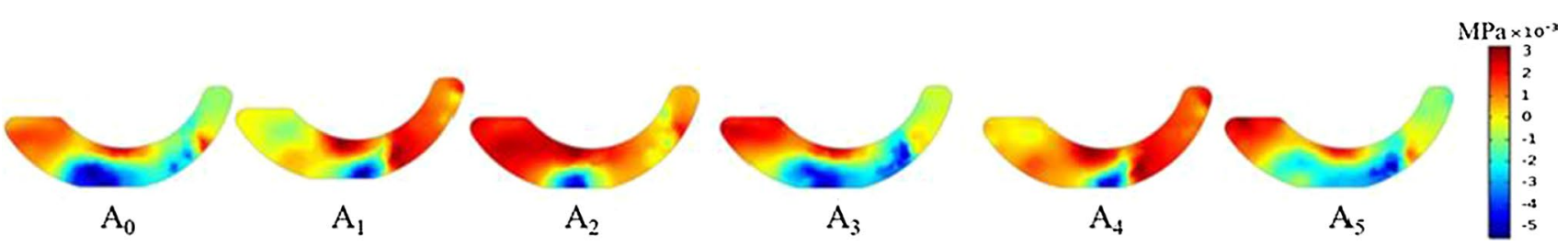

Fig. 12 Pressure distribution at cross section of the oil inlet chamber 


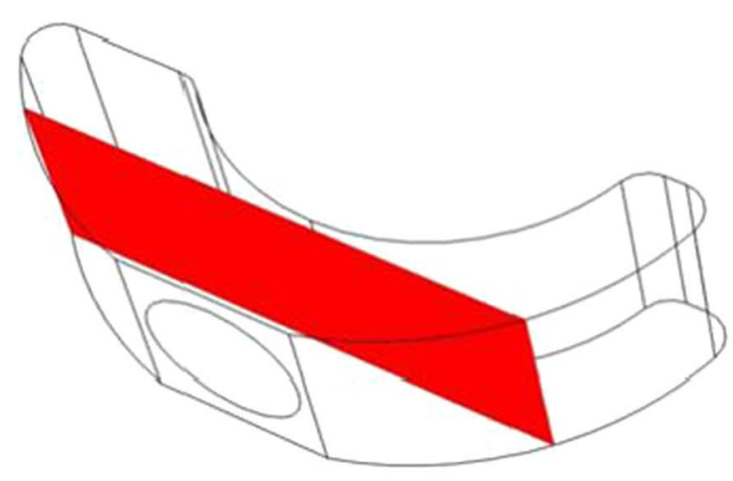

(a)

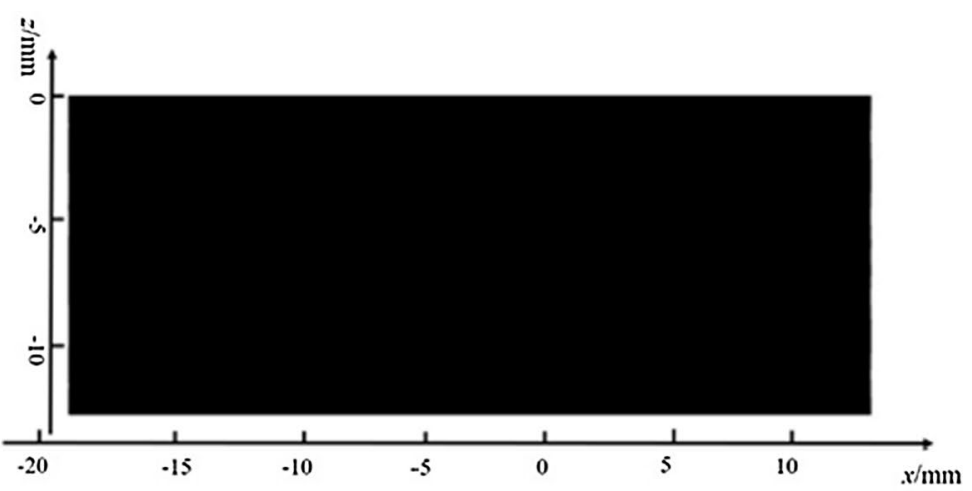

(b)

Fig. 13 Longitudinal section through the inlet chamber

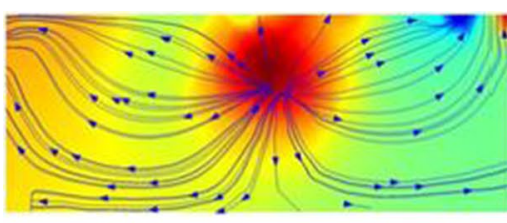

$\mathrm{A}_{0}$

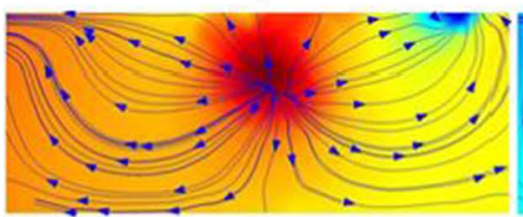

$\mathrm{A}_{3}$

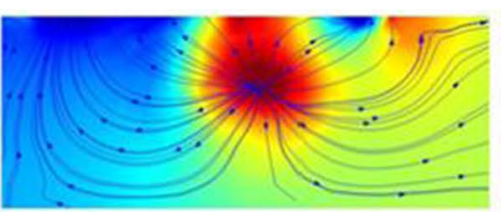

$\mathrm{A}_{1}$

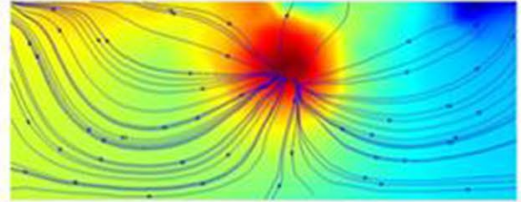

$\mathrm{A}_{2}$

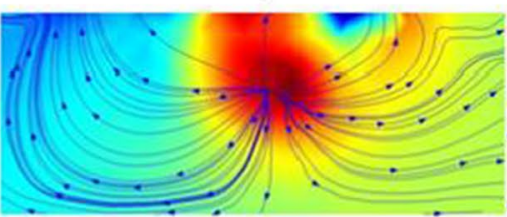

$\mathrm{A}_{4}$

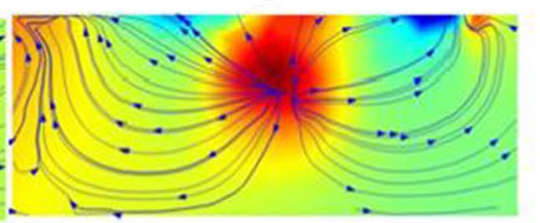

$\mathrm{A}_{5}$

Fig. 14 Pressures and streamline distribution in the longitudinal section through the inlet chamber

\subsection{Analysis of cross and longitudinal section of oil discharge chamber}

The flow characteristics of the cross and longitudinal sections through the oil discharge chamber are further analyzed, where $\mathrm{A}_{6} \rightarrow \mathrm{A}_{11}$ corresponds to the motion of the rotating region.

Figure 15 is the pressure distribution at the cross section through the discharge chamber.

The pressure on the left side of the oil discharge chamber is higher than the pressure on the right side, which is consistent with the pressure distribution within the rotation zone.

In order to further study the flow through the oil drainage chamber, a longitudinal section of the oil drainage chamber was selected for analysis. Figure $16 \mathrm{a}, \mathrm{b}$ is the longitudinal section through the discharge chamber and its $x$ and $z$ coordinate distributions.

Figure 17 is a pressure and streamlines distribution diagram of the longitudinal section of the discharge chamber.

By analyzing Fig. 17, it can be concluded that in the area of the oil discharge chamber $A_{6} 、 A_{7} 、 A_{9} 、 A_{10}$ and $A_{11}$, the pressure on the right side is lower than that on the left side. In $A_{8}$, the pressure on the right side is higher than that on the left side, which is closely related to the structure of the oil discharge chamber.

By studying the streamline distribution of Fig. 17, it is concluded that in the $z<-8 \mathrm{~mm}$ area, the left side has a greater ability to squeeze the oil than the right side, and the pressure difference causes the oil to flow laterally, which hinders the right side from flowing out of the oil outlet pipe, thus reducing the outlet flow.

\section{Improved design of cycloid pump}

\subsection{Improved design of oil inlet and outlet chambers}

According to the flow characteristics of the oil inlet chamber, Fig. $18 \mathrm{a}, \mathrm{b}$ is the $x-z$ coordinate distribution diagram of the unoptimized and optimized, respectively, and the 


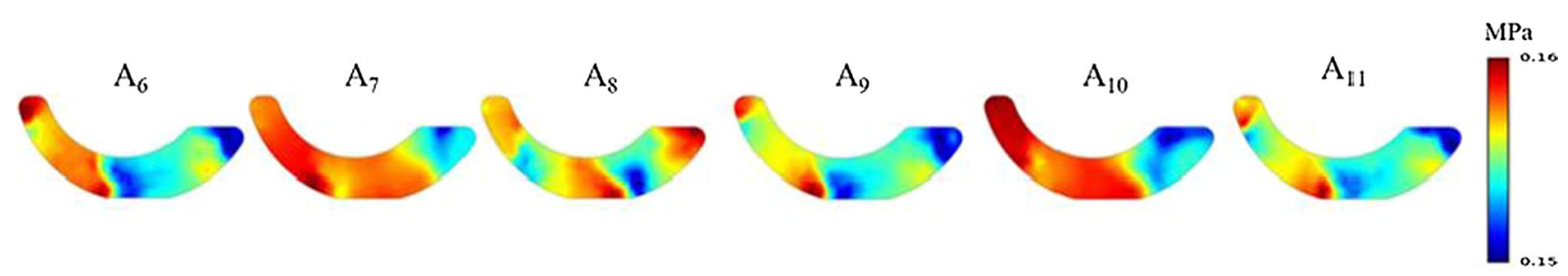

Fig. 15 Pressure distribution at the cross section of the discharge chamber

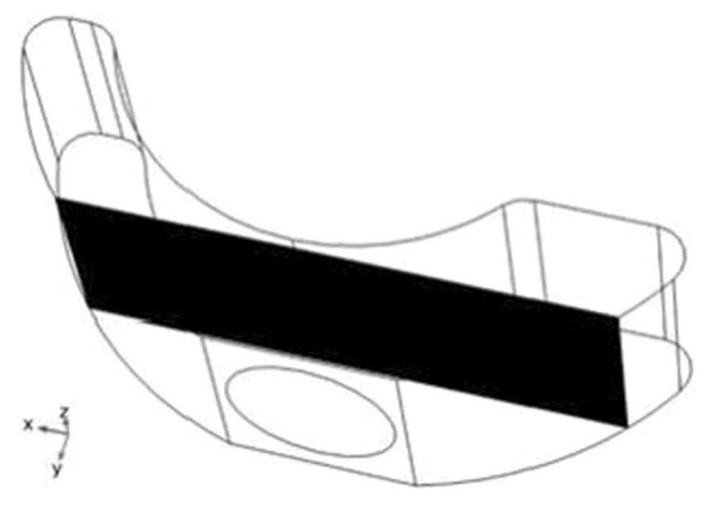

(a)

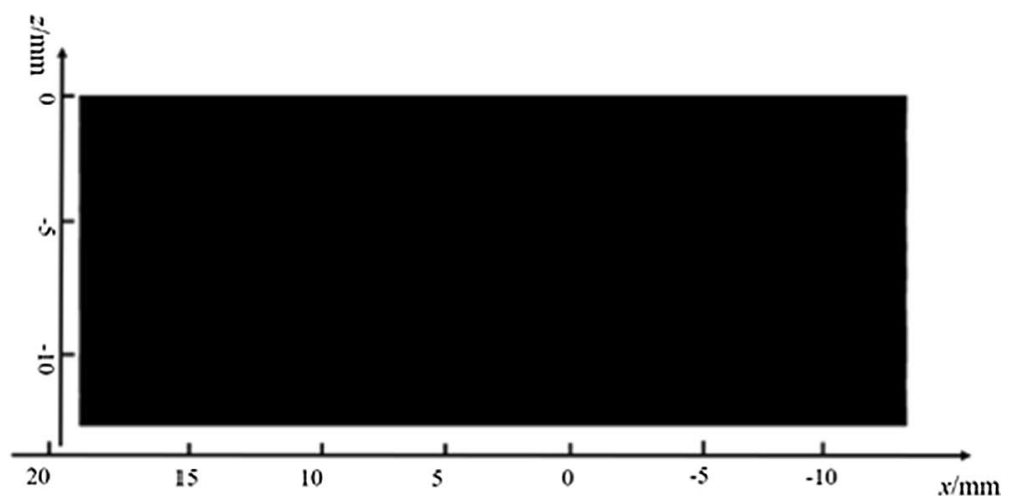

(b)

Fig. 16 Schematic diagram of longitudinal section of the oil discharge chamber

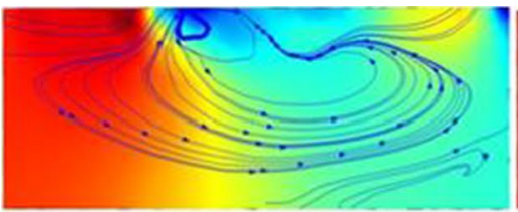

$\mathrm{A}_{6}$

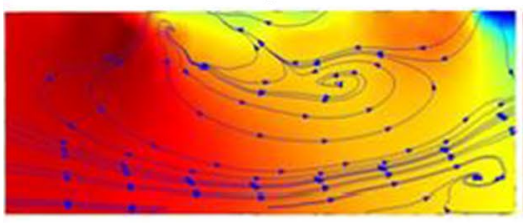

$\mathrm{A}_{9}$

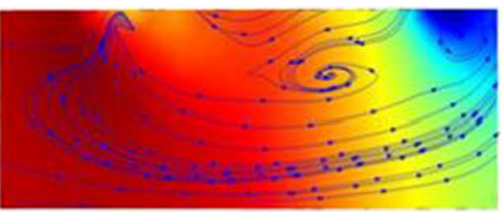

$\mathrm{A}_{7}$

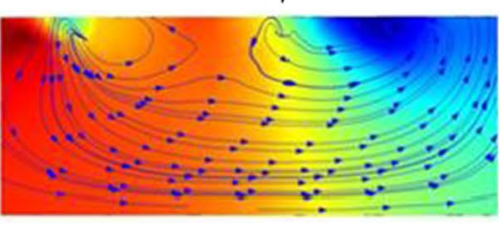

$\mathrm{A}_{10}$

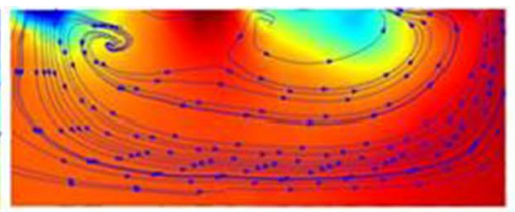

$\mathrm{A}_{8}$

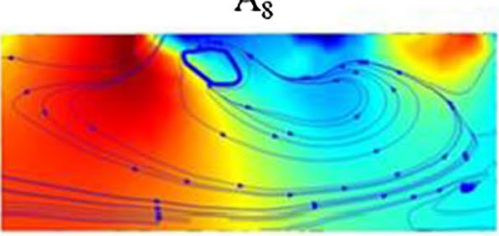

$\mathrm{A}_{11}$

Fig. 17 Pressures and streamline distribution in the longitudinal section of the discharge chamber

inlet is the connection between the oil inlet pipe and the oil inlet chamber.
In order to reduce the large lateral flow of liquid in the range of $z<-8 \mathrm{~mm}$ and $-18 \mathrm{~mm}<x<-5 \mathrm{~mm}$, a plane with $z=-8 \mathrm{~mm}$ is used to reduce the lower negative 


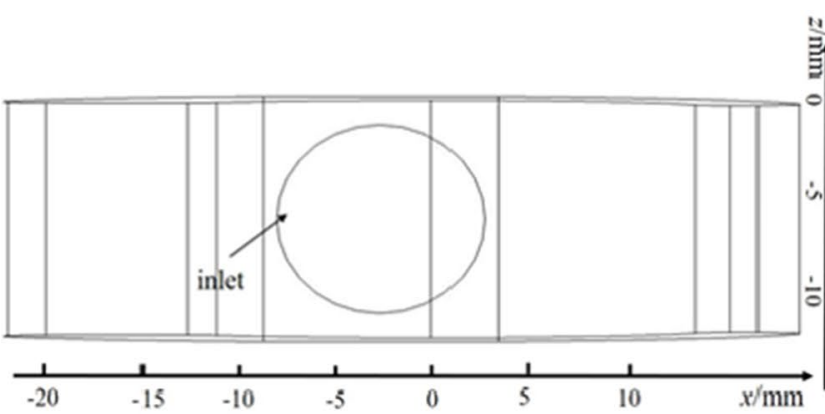

(a)

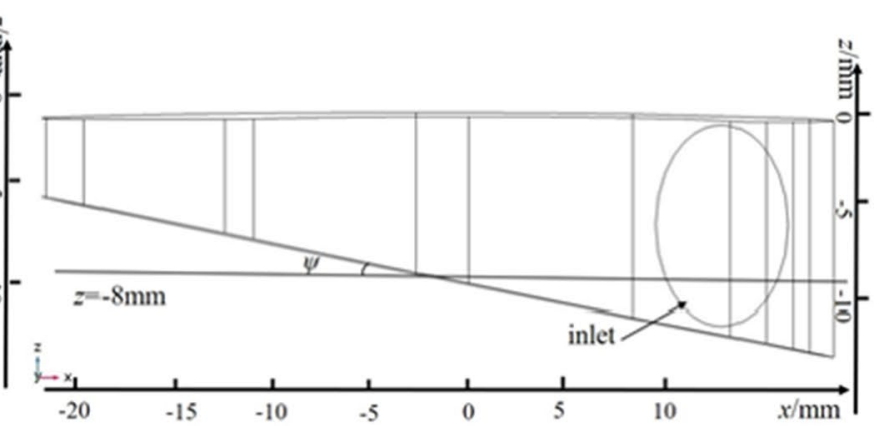

(b)

Fig. $18 x-z$ coordinate of the inlet chamber

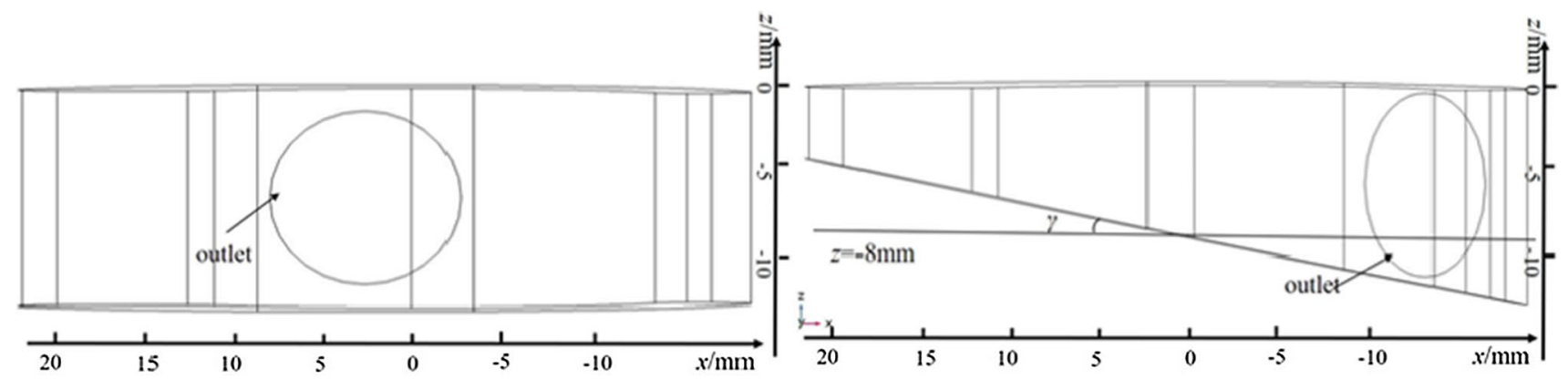

Fig. $19 x-z$ coordinate of the outlet chamber

pressure of the oil inlet chamber by rotating the plane by $\psi$ angle. The optimized slope can reduce the lateral movement speed of the oil entering the oil chamber and increase the $\mathrm{z}$-axis movement speed, so that the oil is sucked into the rotating area between the rotors.

Figure $19 \mathrm{a}$ and $\mathrm{b}$ is the $x-z$ coordinate distribution diagram of the unoptimized and optimized, respectively, and the outlet is the connection between the oil outlet pipe and the oil outlet chamber.

In order to reduce the lateral flow caused by the pressure difference in the area of $z<-8 \mathrm{~mm}$, a plane of $z=-8 \mathrm{~mm}$ is used to optimize the oil discharge chamber by rotating the plane $\gamma$ angle, and the outlet is moved to the right side to make better use of the pressure difference between the left and right sides to drain the oil, the optimized slope can reduce the lateral movement speed of the oil discharged from the rotating area and increase the movement speed of the $z$-axis direction of the oil, so that the oil can be sucked out smoothly.

Take $\psi, \gamma$ as $11.5^{\circ}$ to optimize the design of the oil inlet and outlet chambers and carry out FSI simulation analysis on the improved cycloid pump. Fig. 20 is the model diagram of cycloidal pump after the optimization of inlet and outlet chambers.

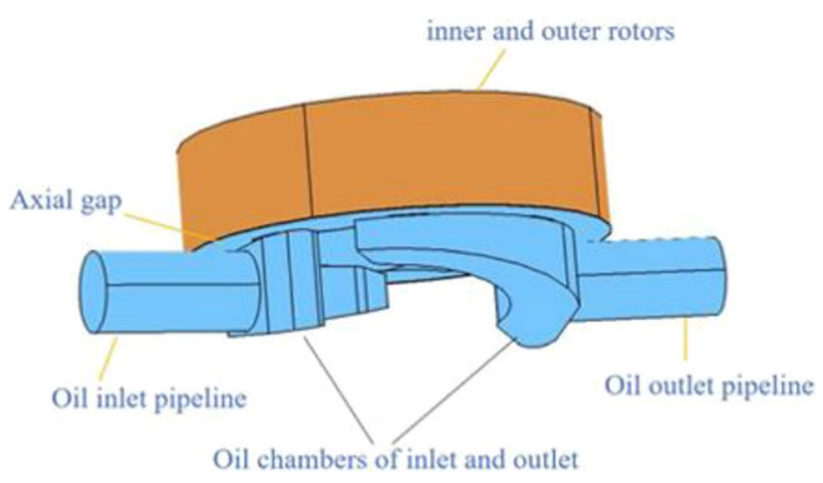

Fig. 20 Cycloidal pump model after optimization

\subsection{Comparison before and after optimization}

Fig. 21a, b shows the instantaneous flow and pressure in the inlet of optimized and unoptimized.

Table 8 shows the comparative analysis of the inlet and outlet flow of cycloidal pump before and after optimization.

Through analyzing Fig. 21 and Table 8, it can be concluded that after the optimization of the oil inlet chamber, the inlet flow of the cycloid pump increased by $5.8 \%$ compared with the unoptimized, the inlet flow pulsation decreased by $32.7 \%$; the inlet pressure decreased by $5.8 \%$ 


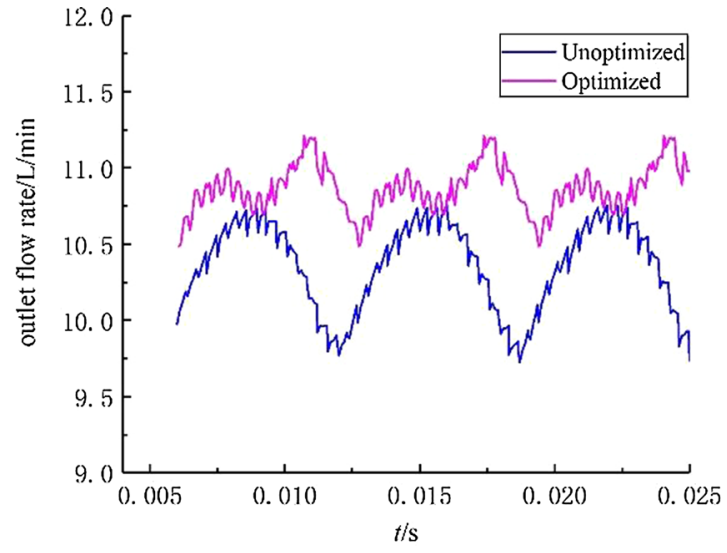

(a)

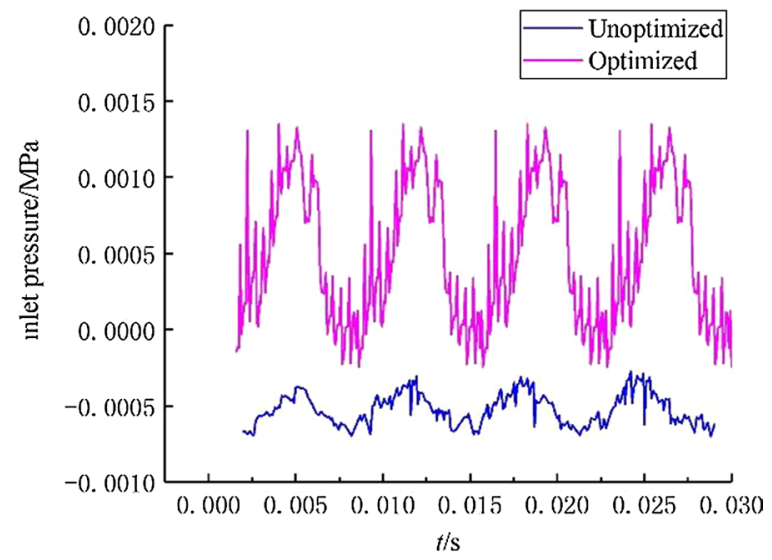

(b)

Fig. 21 Comparisons of the inlet instantaneous flow and pressure

Table 8 Comparisons and analysis of inlet flow pressure characteristics of optimized and unoptimized

\begin{tabular}{lllrl}
\hline & $Q_{m} / \mathrm{L} / \mathrm{min}$ & $P_{m} / \mathrm{MPa}$ & $\delta_{Q} / \%$ & $\delta_{P} / \%$ \\
\hline experiment & 9.911 & 0.143 & 3.9 & 26.7 \\
FSI & 9.948 & 0.151 & 33.9 & 3.4 \\
Improvement $/ \%$ & 0.37 & 5.3 & 88.5 & 685 \\
\hline
\end{tabular}

compared with the unoptimized, and the pressure pulsation rate increased by $298 \%$. After optimization, the inlet flow and flow pulsation of the pump are increased, the flow characteristics are improved, the inlet pressure is reduced, the suction pressure is increased, and the pressure pulsation is also increased, so the other characteristics of the pump are improved except for the increase in pressure pulsation.
Fig. 22a and $\mathrm{b}$ shows the curve of outlet instantaneous flow and pressure, and Table 9 shows the average value of outlet flow, flow pulsation rate, pressure mean value and pressure pulsation rate.

Through analyzing Fig. 22 and Table 9, it can be concluded that after optimizing the discharge chamber, the discharge flow of the cycloid pump increased by $16.3 \%$, the pulsation rate of discharge flow decreased by $47 \%$, the outlet pressure decreased by $2.7 \%$ and the pulsation rate decreased by $8.2 \%$. After optimization, the outlet flow of the pump increases and the flow pulsation decreases, the flow characteristics are improved, the outlet pressure is slightly reduced, and the pressure pulsation is also reduced.

Based on the above analysis, it can be concluded that the flow and pressure pulsation of the cycloid pump are reduced, and the average flow is increased, which is feasible.

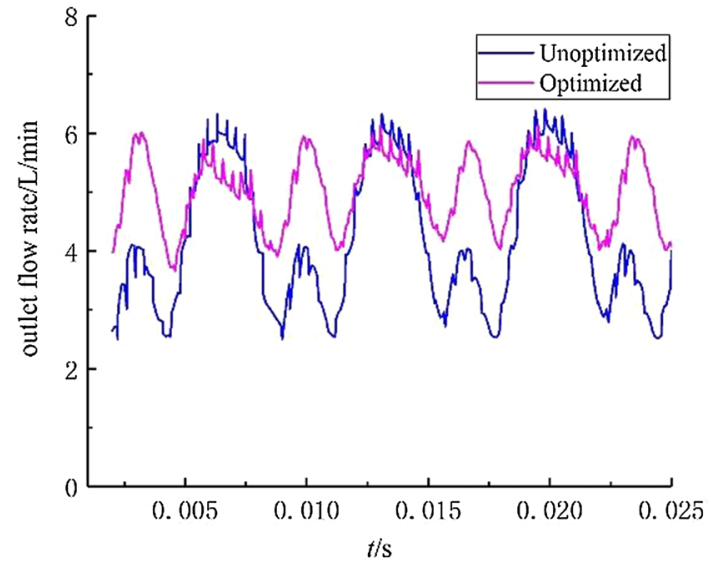

(a)

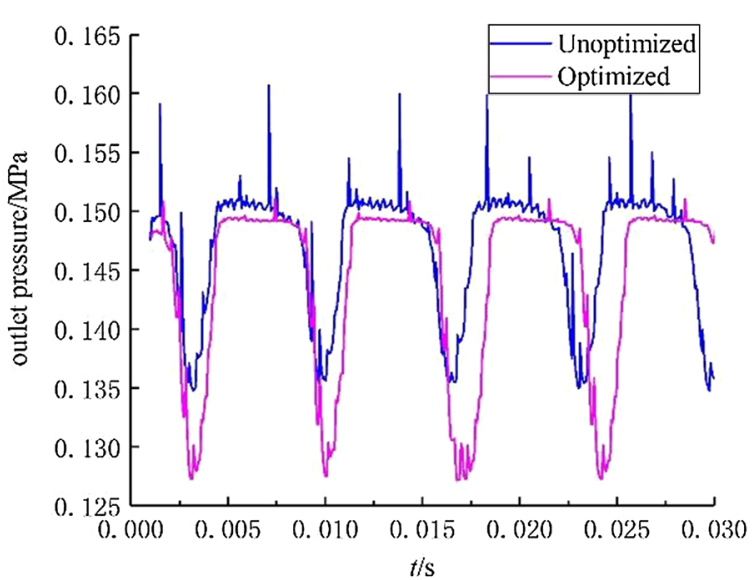

(b)

Fig. 22 Comparisons of outlet instantaneous flow and pressure 
Table 9 Comparisons of outlet flow pressure characteristics of optimized and unoptimized

\begin{tabular}{lclll}
\hline & $Q_{m} / \mathrm{L} / \mathrm{min}$ & $\delta_{Q} / \%$ & $P_{m} / \mathrm{MPa}$ & $\delta_{P} / \%$ \\
\hline Unoptimized & 4.3 & 93 & 0.148 & 18.2 \\
optimized & 5.0 & 49.3 & 0.144 & 16.7 \\
Improvement $/ \%$ & 16.3 & -47.0 & -2.7 & -8.2 \\
\hline
\end{tabular}

\section{Conclusion}

CFD and FSI simulation of the cycloid pump are carried out and compared with the experiment; it is found that FSI simulation results are closer to the reality. Based on the simulation results of FSI, the rotating domain and the flow field of the oil inlet and outlet chambers of the cycloid pump are analyzed and the improved design scheme is proposed.

Based on the reliability of FSI simulation, the rotating region and oil inlet and outlet chambers of the cycloid pump are further analyzed. The negative pressure: $A_{0} \rightarrow A_{2}>A_{3} \rightarrow A_{5}$, the positive pressure: $A_{6} \rightarrow A_{8}<A_{9} \rightarrow A_{11}$. Through the analysis of the oil inlet and outlet chamber, the oil appears a lateral flow, and the transverse flow of the oil hinders the fluid flow in and out resulting in the decrease in the outlet flow.

Based on the analysis of the flow field of cycloidal pump, according to the distribution of the pressure in the rotating region and the inlet and outlet chambers, the fluid movement is driven by the pressure difference, and the horizontal flow occurs in the inlet and outlet chambers due to the different oil suction or discharge capacities in different regions. The inclined plane design is used to reduce the volume of the areas with weak oil suction or discharge energy and to promote the better vertical flow of the fluid, so as to achieve the purpose of improved design.

Finally, the flow and pressure characteristics of the optimized and the unoptimized cycloidal pumps are compared; it is found that the inlet flow of the cycloid pump increased by $5.8 \%$ compared with the unoptimized, the inlet flow pulsation decreased by $32.7 \%$. The discharge flow of the cycloid pump increased by $16.3 \%$, the pulsation rate of discharge flow decreased by $47 \%$. The flow and pressure characteristics at the inlet and outlet of the cycloid pump have been improved.

Acknowledgements I would like to thank Prof. Liu and Prof. Wang for their guidance on paper writing, Prof. Mao Hu-ping for their help in the experiment, and finally, I would like to thank International Science Editing for their help in language modification.

Funding This project is supported by Applied Basic Research Programs of Shanxi Province in China (201901D111131) and National Defense Science and Technology Key Laboratory of Tank Transmission (141009AT03091H).

\section{Declarations}

Conflict of interest I solemnly declare that the paper submitted is the result of the author's independent research. Except for the quoted contents, this paper does not contain any scientific research achievements that have been published or written by other individuals or groups. I am fully aware that the legal responsibility of this statement is borne by me.

Open Access This article is licensed under a Creative Commons Attribution 4.0 International License, which permits use, sharing, adaptation, distribution and reproduction in any medium or format, as long as you give appropriate credit to the original author(s) and the source, provide a link to the Creative Commons licence, and indicate if changes were made. The images or other third party material in this article are included in the article's Creative Commons licence, unless indicated otherwise in a credit line to the material. If material is not included in the article's Creative Commons licence and your intended use is not permitted by statutory regulation or exceeds the permitted use, you will need to obtain permission directly from the copyright holder. To view a copy of this licence, visit http://creativecommons.org/licenses/by/4.0/.

\section{References}

1. Saegusa Y, Urashima K, Sugimoto M, Onoda M, Koiso T (1984) Development of oil-pump rotors with a trochoidal tooth shape. SAE Trans 93:359-364

2. Fabiani M, Mancò S, Nervegna N, Rundo M, Armenio G, Pachetti C, Trichilo R (1999) Modelling and simulation of gerotor gearing in lubricating oil pumps. SAE Technical Paper (No 1999-01-0626)

3. Liu H, Lee J-C, Yoon A, Kim S-T (2015) Profile design and numerical calculation of instantaneous flow rate of a gerotor pump. JAMP 03:92-97. https://doi.org/10.4236/jamp.2015.31013

4. Hwang Y-W, Hsieh C-F (2007) Geometric design using hypotrochoid and nonundercutting conditions for an internal cycloidal gear. J Mech Des 129:413-420. https://doi.org/10.1115/1.24378 06

5. Choi TH, Kim MS, Lee GS, Jung SY, Bae JH, Kim C (2012) Design of rotor for internal gear pump using cycloid and circulararc curves. J Mech Des 134:011005. https://doi.org/10.1115/1. 4004423

6. Jung S-Y, Bae J-H, Kim M-S, Kim C (2011) Development of a new gerotor for oil pumps with multiple profiles. Int J Precis Eng Manuf 12:835-841. https://doi.org/10.1007/s12541-011-0111-y

7. Frosina E, Senatore A, Buono D, Santato L (2015) Analysis and simulation of an oil lubrication pump for internal combustion engines. J Fluids Eng 137:051102. https://doi.org/10.1115/1. 4029442

8. Gamez-Montero P-J, Castilla R, del Campo D, Ertürk N, Raush G, Codina E (2012) Influence of the interteeth clearances on the flow ripple in a gerotor pump for engine lubrication. Proc Institution of Mec Eng Part D J Automob Eng 226:930-942. https://doi.org/10. 1177/0954407011431545

9. Castilla R, Gamez-Montero PJ, Raush G, Codina E (2017) Method for fluid flow simulation of a gerotor pump using openFOAM. J Fluids Eng 139:111101. https://doi.org/10.1115/1.4037060

10. Rundo M (2017) Models for flow rate simulation in gear pumps: a review. Energies 10:1261. https://doi.org/10.3390/en10091261

11. Natchimuthu K, Sureshkumar J, Ganesan V (2010) CFD Analysis of flow through a gerotor oil pump. SAE Technical Paper (No 2010-01-1111)

12. Frosina E, Senatore A, Buono D, Manganelli MU, Olivetti M (2014) A tridimensional CFD analysis of the oil pump of an high 
performance motorbike engine. Energy Procedia 45:938-948. https://doi.org/10.1016/j.egypro.2014.01.099

13. Suresh Kumar M, Manonmani K (2010) Computational fluid dynamics integrated development of gerotor pump inlet components for engine lubrication. Pro Inst Mech Eng Part D J Automob Eng 224:1555-1567. https://doi.org/10.1243/09544070JAUTO15 94

14. Suresh Kumar M, Manonmani K (2011) Numerical and experimental investigation of lubricating oil flow in a gerotor pump. IntJ Automot Technol 12:903-911. https://doi.org/10.1007/ s12239-011-0103-Z

15. Zhang D, Perng CY, Laverty M (2006) Gerotor oil pump performance and flow/pressure ripple study. SAE Trans 115:204-209

16. Altare G, Rundo M (2016) Computational fluid dynamics analysis of gerotor lubricating pumps at high-speed: geometric features influencing the filling capability. J Fluids Eng 138:111101. https:// doi.org/10.1115/1.4033675

17. Buono D, Siano D, Frosina E, Senatore A (2017) Gerotor pump cavitation monitoring and fault diagnosis using vibration analysis through the employment of auto-regressive-moving-average technique. Simul Model Pract Theory 71:61-82. https://doi.org/ 10.1016/j.simpat.2016.11.005

18. Ruvalcaba MA, Hu X (2011) Gerotor fuel pump performance and leakage study. in: volume 6: fluids and thermal systems; advances for process industries, Parts A and B. ASMEDC, Denver, Colorado, USA, pp 807-815

19. Ahamed MdF (2018) The fluid structure interaction analysis of a peristaltic pump

20. Takashi N, Hughes TJR (1992) An arbitrary Lagrangian-eulerian finite element method for interaction of fluid and a rigid body. Comput Methods Appl Mech Eng 95:115-138. https://doi.org/ 10.1016/0045-7825(92)90085-X

21. Sarrate J, Huerta A, Donea J (2001) Arbitrary Lagrangian-eulerian formulation for fluid-rigid body interaction. Comput Methods Appl Mech Eng 190:3171-3188. https://doi.org/10.1016/S00457825(00)00387-X

22. Bathe K-J, Zhang H, Ji S (1999) Finite element analysis of fluid flows fully coupled with structural interactions. Comput Struct 72:1-16. https://doi.org/10.1016/S0045-7949(99)00042-5

23. Dettmer W, Perić D (2006) A computational framework for fluidrigid body interaction: Finite element formulation and applications. Comput Methods Appl Mech Eng 195:1633-1666. https:// doi.org/10.1016/j.cma.2005.05.033

Publisher's Note Springer Nature remains neutral with regard to jurisdictional claims in published maps and institutional affiliations. 